\title{
PENGARUH CORPORATE GOVERNANCE DAN CORPORATE REPUTATION TERHADAP EMPLOYEE ENGAGEMENT (Studi pada sebuah perusahaan logistik multinasional di Indonesia)
}

\author{
Haryanto 1 \\ STIE Mulia Singkawang
}

\begin{abstract}
The purpose of this study was to determine whether there is a relationship between Corporate Governance and Corporate Reputation on Employee Engagement. This research was conducted at a multinational logistics company in Indonesia in December 2020. The data collection method was carried out by means of a questionnaire via google form which was distributed to employees. Data analysis was performed using Statistical Product and Service Solutions with classical tests. Researcher found several things, including Corporate Governance partially has a significant and positive effect on Employee Engagement, Partially Corporate Reputation has a significant and positive effect on Employee Engagement, Corporate Governance and Corporate Reputation simultaneously have a significant and positive effect on Employee Engagement.
\end{abstract}

Keywords: Corporate Governance, Corporate Reputation, Employee Engagement. Logistics Company

\begin{abstract}
ABSTRAK
Tujuan dari penelitian ini adalah untuk mengetahui apakah terdapat hubungan antara tata Kelola perusahaan dan reputasi perusahaan terhadap keterlibatan karyawan. Penelitian ini dilakukan di sebuah perusahaan logistik multinasional di Indonesia pada bulan Desember 2020. Metode pengumpulan data dilakukan dengan menggunakan kuesioner melalui google form yang disebarkan kepada karyawan. Analisis data dilakukan dengan menggunakan Produk Statistik dan Solusi Layanan dengan tes klasik. Peneliti menemukan beberapa hal, diantaranya tata Kelola perusahaan secara parsial berpengaruh signifikan dan positif terhadapketerlibatan karyawan, Secara parsial reputasi perusahaan berpengaruh signifikan dan positif terhadap keterlibatan karyawan, tata kelola perusahaan dan reputasi perusahaan secara simultan berpengaruh signifikan dan positif terhadap keterlibatan karyawan.
\end{abstract}

Kata Kunci: Tata Kelola Perusahaan, Reputasi Perusahaan, Keterlibatan Karyawan. Perusahaan Logistik

\section{PENDAHULUAN}

Pandemi Coronavirus Disease 2019 (COVID-19) memiliki dampak yang sangat serius di Indonesia dimana pertumbuhan ekonomi di kuartal III tahun 2020 terkontraksi -3,49 persen (Fauzia, 2020). Dengan adanya pertumbuhan negatif yang juga terjadi di kuartal II tahun 2020, maka Indonesia telah resmi masuk ke dalam barisan negara yang mengalami resesi.

Outlook ekonomi yang demikian sulit merupakan tantangan bagi semua korporasi untuk berupaya keras agar dapat bertahan hidup dalam situasi yang serba tidak menentu. Untuk dapat bertahan hidup, maka setiap perusahaan dituntut mampu memenangkan kompetisi dengan para pesaing di masing-masing industri bisnisnya, karena sangat jarang sekali kita temui perusahaan yang beroperasi dalam pasar monopoli dimana tidak ada persaingan usaha.

\footnotetext{
${ }^{1}$ email: haryanto2689@gmail.com
} 


\section{2 | Bina Ekonomi}

Ada banyak faktor yang akan menjadi elemen penting dan menentukan keberhasilan suatu perusahaan dalam menjalani persaingan usaha. Salah satu elemen paling penting yang dimaksud adalah adanya keterikatan karyawan atau Employee Engagement (EE) perusahaan yang solid, sehingga kebijakan dan strategi yang ditempuh pihak manajemen dapat terlaksana dengan baik.

EE dapat dijelaskan sebagai keterlibatan, kepuasan, antusiasme, motivasi, dan komitmen karyawan untuk menjalankan aktivitas perusahaan dalam rangka mencapai hasil yang unggul (Anand, 2017). Jack Welch, mantan CEO of GE pernah berkata "To win in the marketplace you must first win in the workplace" (Haydon, 2020). Untuk dapat memenangkan persaingan, maka kita harus terlebih dulu menang di tempat kerja kita. Hal ini menandakan bahwa keberadaan karyawan harus menjadi prioritas utama untuk dapat menunjang kemampuan berkompetisi diluar.

Tata kelola perusahaan atau Corporate Governnance (CG) yang baik akan memberikan kontribusi yang baik terhadap jalannya roda organisasi. CG merupakan sistem, aturan, praktik, dan proses yang digunakan perusahaan untuk diarahkan dan dikendalikan. Tata kelola perusahaan mengacu pada keseluruhan sistem untuk mengelola dan mengawasi perusahaan (Bezo \& Dibra, 2020). Dewan direksi dan dewan komisaris bertanggung jawab untuk mengembangkan suatu tata kelola perusahaan yang baik yang akan memimpin perusahaan untuk mencapai tujuannya. Suatu tata kelola perusahaan yang baik memastikan bahwa lingkungan bisnis adil dan transparan serta perusahaan dapat dipertanggungjawabkan atas tindakan mereka. Tata kelola perusahaan yang baik juga memerlukan kerjasama dari semua pihak, mulai dari pimpinan puncak, para komisaris, para manajemen puncak, sampai dengan karyawan operasional. Dengan adanya kerjasama dari semua pihak, maka aktivitas perusahaan seperti pengumpulan informasi, penyebaran informasi, serta interpretasi informasi akan menjadi lebih efektif dan efisien. CG yang baik merupakan dasar pemahaman awal karyawan tentang keyakinan positif bahwa perusahaan berjalan sesuai rambu-rambu yang jelas dan pasti.

Reputasi Korporasi atau Corporate Reputation (CR) mengacu pada bagaimana kelompok pemangku kepentingan eksternal atau pihak berkepentingan lainnya yang benar-benar mengkonseptualisasikan organisasi itu (Tong, 2013). Ada kesepakatan umum bahwa CR merupakan aset tidak berwujud yang cukup menarik dan penting, karena memberikan kontribusi yang signifikan terhadap keunggulan kompetitif organisasi jangka panjang membangun dan memelihara reputasi positif memastikan partisipasi berkelanjutan dari pemangku kepentingan dalam aktivitas perusahaan dan dapat mengintegrasikan perusahaan dengan lebih baik lingkungannya, yang merupakan dasar untuk "kelangsungan hidup dan keuntungan perusahaan yang berkelanjutan" (Luis et al., 2015). CR yang baik akan membuat karyawan merasa lebih dihargai dan dipandang tinggi saat bekerja di perusahaan, sehingga karyawan lebih termotivasi untuk melakukan pekerjaan mereka.

Jadi, dapat disimpulkan bahwa dengan mengutamakan dan melibatkan karyawan, akan memberikan layanan pelanggan yang unggul, kualitas kerja yang lebih tinggi, peningkatan produktivitas dan inovasi, serta efisiensi dan efektivitas pembuatan keputusan, yang mengarah pada kepuasan pelanggan yang meningkat, yang pada gilirannya meningkatkan penjualan dan pendapatan dan pada akhirnya keuntungan pemegang saham. Hal ini akan sangat membantu perusahaan dalam menghadapi perubahan yang tidak terduga seperti pandemi COVID-19 yang terjadi pada saat ini.

Oleh karena itu, keterikatan karyawan dalam perusahaan menjadi hal yang sangat penting dan merupakan salah satu kunci sukses perusahaan. Tanpa adanya keterlibatan karyawan, informasi tidak akan bisa dikumpulkan, disebarkan, diinterpretasikan, dan dijalankan secara efektif dan efisien yang pada akhirnya akan mempengaruhi keberhasilan kebijakan perusahaan.

Berdasarkan fenomena tersebut, maka tujuan penelitian ini adalah untuk mengamati: 
1. Pengaruh Corporate Governance terhadap Employee Engagement dan besaran pengaruhnya

2. Pengaruh Corporate Reputation terhadap Employee Engagement dan besaran pengaruhnya

3. Pengaruh Corporate Governance dan Corporate Reputation terhadap Employee Engagement dan besaran pengaruhnya

\section{STUDI LITERATUR DAN PENGEMBANGAN HIPOTESIS}

\subsubsection{Corporate Governance}

Terminologi Corporate Governance (CG) menjadi lebih signifikan dan kontroversial dalam beberapa dekade belakangan ini terutama di negara-negara maju. Hal ini karena terjadinya banyak skandal keuangan dan akuntansi akibat lemahnya CG di banyak perusahaan. Enron adalah salah satu contoh nyata akibat lemahnya tata kelola perusahaan yang mengakibatkan kegagalan keuangan (Bawaneh, 2020). Kegagalan Enron telah menyebabkan meningkatnya permintaan untuk CG yang lebih baik. Akibat adanya liberalisasi perdangangan, maka fokus penerapan CG yang solid telah menyebar ke negara-negara berkembang. Secara umum negara-negara berkembang tidak memiliki kerangka kerja yang terorganisasi dan diakui secara luas, sehingga mereka tidak dapat melaksanakan CG dengan baik. Banyak penelitian menemukan, bahwa CG di negara berkembang relatif bervariasi dan lemah (Arayssi \& Jizi, 2019).

Elemen CG diperlakukan sebagai sistem check and balances organisasi, karena kebijakan strategis terkait pengungkapan keberlanjutan sangat penting bagi manajemen. Oleh karena itu, CG yang lemah akan gagal berkomunikasi dengan pemangku kepentingan yang berbeda, yang mengakibatkan visibilitas pasar yang lebih rendah dan biaya agensi yang lebih tinggi. Juga terbukti bahwa di negara berkembang, tata kelola perusahaan relatif lemah dan bermasalah karena kurangnya keterlibatan pemangku kepentingan, bisnis yang dikendalikan oleh keluarga, kurangnya supremasi hukum, kurangnya pengendalian korupsi, campur tangan politik, lingkungan kelembagaan yang lemah, dan tidak adanya orang yang berpengetahuan (Bae et al., 2018).

CG yang baik merupakan hal yang sangat penting untuk perkembangan ekonomi negara mana pun, dengan meningkatkan kinerja keuangan perusahaan dan meningkatkan akses mereka ke sumber daya luar. Dalam konteks pasar berkembang, CG yang baik membantu mencapai sejumlah tujuan kebijakan, seperti meminimalkan kemungkinan krisis keuangan, memperkuat hak milik, meminimalkan biaya operasional dan biaya modal, dan mengarah pada pengembangan pasar yang efisien (Naseem et al., 2017). Praktik CG yang baik juga mengurangi risiko investor, menarik investasi untuk modal dan meningkatkan kinerja perusahaan (Chaudhary \& Gakhar, 2018).

CG juga bertujuan untuk mengurangi biaya agensi dengan melindungi kepentingan prinsipal, menyelaraskan kembali kepentingan agen dan prinsipal, mengurangi asimetri informasi antara prinsipal dan agen, serta memastikan pemantauan dan arahan yang memadai kepada agen.

Dapat disimpulkan bahwa CG merupakan suatu struktur yang berperan dan bertanggung jawab terhadap jalannya suatu perusahaan. CG yang baik harus diikuti dengan tingginya independensi dan keterampilan khusus dari dewan komisaris. CG yang baik merupakan hal yang sangat diperlukan bagi negara berkembang seperti Indonesia, karena CG yang baik akan membuat perusahaan lebih terorganisasi dan lebih mudah menanggapi perubahan yang terjadi, sehingga perusahaan tidak tertendang keluar dari persaingan saat terjadi perubahan yang tidak bisa dikendalikan perusahaan, seperti pandemi COVID-19 yang terjadi saat ini. 


\section{4 | Bina Ekonomi}

\subsubsection{Corporate Reputation}

Corporate Reputation (CR) mengacu pada bagaimana kelompok pemangku kepentingan eksternal atau pihak berkepentingan lainnya yang benar-benar mengkonseptualisasikan organisasi itu. Demikian pula, dalam public relations, reputasi perusahaan diekspresikan dalam bentuk representasi kognitif dalam arti kolektif. Seorang pemangku kepentingan memiliki persepsi sendiri terhadap perusahaan yang menjadi bagian dari representasi dalam kolektivitas pemangku kepentingan. Dengan demikian, CR dianggap sebagai konsepsi kolektif di antara sekelompok pemangku kepentingan perusahaan (Tong, 2013).

Apakah reputasi merupakan aset? Pastinya bukan aset tetap yang dapat didepresiasi. Reputasi dapat diklaim sebagai aset tidak berwujud, tetapi menilai reputasi merupakan hal yang sangat kontroversial. Melabeli reputasi sebagai 'aset' lebih mengarah ke aspek emosional daripada finansial, seperti 'kewajiban' yang menunjukkan bahwa ada masalah. Bagaimana cara menentukan nilai reputasi? Bisakah Anda menilainya? Memberi nilai pada suatu reputasi pernah dianggap tidak mungkin, sehingga menghargai reputasi tidak boleh diabaikan untuk masa depan. Namun, harus dipertimbangkan mengapa ada orang yang ingin memberikan nilai kepada reputasi. Ada terlalu banyak faktor yang mempengaruhi nilai reputasi untuk membuat hal ini dapat dijalankan (Brady \& Honey, 2007).

Secara umum telah disepakati CR merupakan aset tidak berwujud yang menarik dan penting, karena memberikan kontribusi yang signifikan dalam membangun sebuah organisasi yang kompetitif dan reputasi positif dalam jangka panjang. Kontribusi CR ini memastikan pemangku kepentingan berpartisipasi secara berkelanjutan dalam aktivitas perusahaan, sehingga perusahaan bisa mengintegrasikan diri dengan lebih baik terhadap lingkungannya, yang merupakan dasar untuk "kelangsungan hidup dan keuntungan perusahaan yang berkelanjutan" (Luis et al., 2015).

Dapat disimpulkan bahwa CR merupakan persepsi dari semua pihak, baik itu dari pemangku kepentingan internal dan eksternal, maupun masyarakat terhadap perusahaan. CR yang baik akan membuat perusahaan tetap dipercaya oleh semua pihak, sehingga tidak mudah goyah pada saat terjadinya perubahan yang tidak bisa dikendalikan oleh perusahaan, seperti pandemi COVID-19 yang terjadi saat ini.

\subsubsection{Employee Engangement}

(Anand, 2017) mendefinisikan Employee Engangement (EE) sebagai:

- keterikatan dan kepuasan individu serta antusiasme untuk bekerja

- kekuatan ilusif yang memotivasi karyawan ke tingkat kinerja yang lebih tinggi

- proses di mana organisasi meningkatkan komitmen dan kelangsungan karyawannya untuk pencapaian hasil yang unggul.

- sebagai keadaan pikiran yang positif, memuaskan, dan berhubungan dengan pekerjaan yang dicirikan oleh semangat, dedikasi, dan penyerapan.

Karyawan yang terikat adalah seseorang yang diberi kompensasi yang baik dan memiliki kepentingan selaras dengan organisasi (Mutnuru, 2016). Keterikatan karyawan bergantung pada tiga kondisi psikologis di tempat kerja: meaningfulness, psychological safety, dan availability.

- Meaningfulness mengacu pada nilai yang karyawan lekatkan pada kinerjanya di dalam peran kerja dia. Hal ini dipengaruhi oleh tugas yang dilakukan karyawan dan peran yang mereka isi.

- Psychological safety mengacu pada pengertian, apakah seseorang menganggap kebebasan menjadi hal yang pasti dalam peran kerja yang ditugaskan padanya. 
- Terakhir, availability melibatkan keyakinan karyawan mengenai apakah mereka memiliki sumber daya fisik, kognitif, dan emosional yang diperlukan untuk berinvestasi sepenuhnya dalam peran kerja mereka. Ini ditentukan sebagian besar oleh persepsi individu tentang kuantitas dan kualitas sumber daya yang tersedia dan tingkat keterlibatan dalam aktivitas di luar pekerjaan.

Secara kolektif, ketiga kondisi diatas menentukan apakah karyawan lebih terikat atau tidak. Keterikatan karyawan sebagai "keterikatan dan kepuasan individu serta antusiasme untuk bekerja" dan "pengalaman yang baik dalam keterikatan dengan aktivitas yang memenuhi secara pribadi meningkatkan rasa keberhasilan profesional anggota staf" (Mutnuru, 2016).

Dapat disimpulkan bahwa EE merupakan suatu proses melibatkan karyawan dalam semua aktivitas yang terjadi di dalam perusahaan dengan tanpa adanya unsur paksaan yang dirasakan oleh karyawan. EE yang baik dapat meningkatkan efisiensi serta efektivitas pengumpulan, penyebaran, serta interpretasi informasi sehingga keputusan yang dilakukan oleh perusahaan dapat dilaksanakan dengan baik. Hal ini tentunya menjadi sangat penting pada saat ini, dimana persaingan di dunia usaha saat ini semakin ketat dan sedang terjadi pandemi COVID-19 yang menyebabkan perusahaan harus bisa merespon secara cepat terhadap perubahan yang terjadi.

\subsubsection{Hubungan Corporate Governance dengan Employee Engangement}

Pengawasan dewan komisaris yang efektif atas keterikatan karyawan harus mencakup halhal berikut:

1. Artikulasi yang jelas tentang pentingnya keterikatan karyawan dan tanggung jawab manajemen untuk mengembangkan dan mempertahankan tingkat keterikatan yang tinggi

2. Komunikasi tentang harapan bahwa keterikatan karyawan diukur dengan tepat

3. Evaluasi berkala atas keterikatan karyawan terhadap metrik yang ditetapkan

4. Evaluasi upaya manajemen untuk meningkatkan keterikatan karyawan

5. Umpan balik dewan untuk upaya keterikatan

Dewan komisaris harus mulai dengan mengembangkan pemahamannya sendiri tentang pentingnya keterlikatan karyawan dalam memenuhi tujuan strategis. Pemahaman ini harus dikomunikasikan kepada manajemen dan diartikulasikan secara eksplisit sebagai bagian dari tanggung jawab manajemen. Jika tujuan keterikatan karyawan terkait dengan kompensasi manajemen, komite kompensasi harus berhati-hati untuk fokus pada tren jangka panjang daripada target tahunan, karena pengukuran keterikatan sangat subjektif dan dapat dipengaruhi oleh banyak variabel di luar kendali manajemen (Lightle et al., 2015).

Berdasarkan penjelasan yang dilakukan, maka hipotesis pertama dalam penelitian ini adalah sebagai berikut:

H1: Corporate Governance bepengaruh positif terhadap Employee Engangement.

\subsubsection{Hubungan Corporate Reputation dengan Employee Engangement}

Penelitian yang dilakukan oleh Gatzert dan Schmit (2016) menunjukkan bahwa Corporate Reputation (CR) yang baik secara positif memengaruhi perilaku pemangku kepentingan. Pengaruh yang paling penting adalah terhadap perilaku pelanggan. Perusahaan dengan reputasi yang lebih baik juga umumnya memiliki keuntungan dalam mempekerjakan karyawan, menghasilkan lebih banyak pelamar kerja, serta kualitas pelamar yang lebih tinggi (Gatzert \& Schmit, 2016).

Studi yang ada telah mengungkap hubungan positif antara berbagai aspek keterikatan karyawan dan kinerja bisnis. Kepuasan dan kinerja karyawan di tempat kerja berkontribusi pada 


\section{6 | Bina Ekonomi}

profitabilitas dan pertumbuhan perusahaan, sementara kualitas kerja karyawan berkontribusi pada inovasi organisasi. Rasio yang tinggi antara jumlah karyawan yang terikat dan jumlah karyawan yang tidak terikat memastikan kinerja keuangan yang unggul dalam suatu organisasi. Organisasi kelas dunia diklaim memiliki rasio keterikatan karyawan 9,57. Terlepas dari bukti pentingnya keterikatan, sangat sedikit penelitian empiris yang menyelidikinya. Keterikatan karyawan dan hasil bisnis berbagi hubungan yang proporsional langsung (Mutnuru, 2016).

Dapat disimpulkan bahwa CR yang baik akan lebih memudahkan perusahaan dalam mencari karyawan karena calon pelamar lebih percaya terhadap perusahaan tersebut. Dengan tingginya tingkat kepercayaan karyawan terhadap perusahaan, maka tingkat partisipasi karyawan di dalam perusahaan akan meningkat secara bersama.

Berdasarkan penjelasan yang dilakukan, maka hipotesis kedua dalam penelitian ini adalah sebagai berikut:

H2: Corporate Reputation bepengaruh positif terhadap Employee Engangement.

\subsubsection{Hubungan Corporate Governance dan Corporate Reputation dengan Employee Engangement}

Penelitian yang dilakukan oleh Derevianko (2018) menunjukkan Sistem Manajemen Reputasi (SMR) terjadi transfer bertahap fungsi manajemen reputasi dari manajer ke pemangku kepentingan perusahaan, yaitu aktivitas reputasi tradisional manajemen dan personel perusahaan digantikan oleh keterlibatan pemangku kepentingan. Terbukti juga bahwa tingkat pelaksanaan SMR harus tinggi, tetapi tidak ditujukan untuk melibatkan manajemen dan personel perusahaan untuk menjaga reputasinya, tetapi lebih kepada melibatkan para pemangku kepentingan untuk mengelola reputasi perusahaan (Derevianko, 2018). Melibatkan pemangku kepentingan dalam proses manajemen reputasi, termasuk melalui penggunaan aktivitas mereka di internet dan jejaring sosial adalah cara untuk mengurangi aktivitas dukungan reputasi manajemen dan staf perusahaan yang irasional.

Dapat disimpulkan bahwa CG yang baik memungkinkan terjadinya aktivitas operasional perusahaan yang lancar, sehingga persepsi semua pihak terhadap perusahaan akan meningkat. Hal ini tentunya akan meningkatkan CR di mata semua pihak, karena salah satu alasan tingginya CR adalah persepsi dari semua pihak yang baik. Dengan adanya CR yang baik ini, maka tingkat EE di dalam perusahaan akan meningkat.

Berdasarkan penjelasan yang dilakukan, maka hipotesis ketiga dalam penelitian ini adalah sebagai berikut:

H3: Corporate Governance dan Corporate Reputation secara simultan bepengaruh positif terhadap Employee Engangement.

\section{METODE DAN DATA}

Berdasarkan hipotesis-hipotesis yang dibuat, maka dapat dikembangkan model penelitian sebagai berikut: 


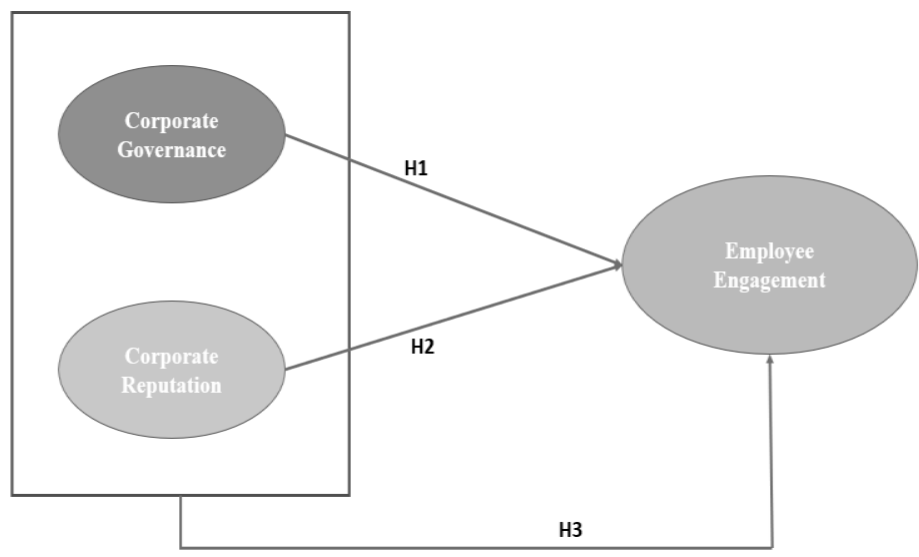

Gambar 1. Model Penelitian

Gambar 1 diatas merupakan bagan model penelitian ini. Berdasarkan model penelitian tersebut maka dapa dilihat bahwa tujuan penelitian ini adalah untuk mengamati pengaruh antar variabel yaitu CG dan CR terhadap EE. Dengan model penelitian ini diharapkan dapat diketahui pola hubungan antar variabel tersebut beserta besaran pengaruhnya khususnya di sebuah perusahaan logistik multinasional dimana penelitian ini telah dilakukan.

\section{Metode Pengumpulan Data}

Pengumpulan data untuk penelitian ini dilakukan melalui penyebaran kuesioner google form kepada karyawan perusahaan di bulan Desember 2020. Responden yang ikut berpartisipasi adalah semua level karyawan dari mulai staf bagian lapangan sampai dengan para direksi perusahaan. Seluruh karyawan perusahaan logistik multinasional ini memiliki akses internet, baik melalui handphone ataupun komputer. Oleh karena itu, pengumpulan data dapat dilakukan dengan relatif cepat. Kuesioner online dibagikan kepada karyawan, baik yang berkantor di Jakarta maupun di kantor cabang, seperti Semarang, Surabaya, dan Medan.

Data kuesioner yang telah diisi secara langsung menjadi bagian dari tabulasi data dalam format excel yang akan memudahkan proses analisis berikutnya. Identifikasi karyawan perusahaan dilakukan dengan memberikan pilihan kelompok berdasarkan gender dan masa kerja tanpa mewajibkan untuk menyebutkan nama karyawan. Tidak dicantumkannya identitas nama karyawan bertujuan untuk memberikan tingkat kepercayaan atas validitas dan reliabilitas data yang diperoleh.

\section{Metode Pengolahan Data}

Terdapat beberapa langkah yang digunakan dalam pengujian hipotesis penelitian ini, yaitu:

\section{○ Analisis Deskriptif}

Menurut (Sugiyono, 2013), analisis deskriptif adalah statistik yang digunakan untuk menganalisis data dengan cara mendeskripsikan atau menggambarkan data yang telah terkumpul sebagaimana adanya tanpa bermaksud membuat kesimpulan yang berlaku untuk umum atau generalisasi.

\section{○ Uji Asumsi Klasik}

Model analisis data dalam penelitian ini menggunakan model analisis regresi linier berganda. Sebelum melakukan regresi linier berganda harus dilakukan uji asumsi klasik terlebih dahulu. Pengujian asumsi klasik diperlukan untuk mengetahui apakah hasil regresi yang dilakukan benar-benar bebas dari adanya gejala heteroskedastisitas, gejala multikolineraritas, dan gejala autokorelasi. Penulis menggunakan bantuan SPSS versi 25 dalam uji asumsi klasik. 


\section{○ Uji Normalitas}

Menurut (Priyatno, 2016), Uji Normalitas residual digunakan untuk mengetahui apakah dalam sebuah model regresi, nilai residual memiliki distribusi normal atau tidak. Residual merupakan selisih atau nilai sisa antara variabel dependen (Y) dengan variabel dependen hasil regresi ( $\left.Y^{\prime}\right)$. Model regresi yang baik adalah model yang memiliki data residual yang terdistribusi secara normal. Model regresi dapat dikatakan berdistribusi normal jika signifikansi lebih besar dari 0.05 dan tidak berdistribusi normal jika signifikansi lebih kecil dari 0.05 .

○ Uji Multikolinearitas

Menurut (Priyatno, 2016), Uji Multikolinearitas adalah keadaan dimana antara dua variabel independen atau lebih pada model regresi terjadi hubungan linier yang sempurna atau mendekati sempurna. Model regresi yang baik mensyaratkan tidak terjadi masalah multikolinearitas. Metode yang digunakan untuk mendeteksi ada tidaknya multikolinearitas adalah dengan melihat nilai tolerance dan variance inflation factor (VIF) pada hasil regresi linier. Jika nilai tolerance lebih dari 0,1 dan nilai VIF kurang dari 10, maka tidak terjadi multikolinearitas.

○ Uji Autokorelasi

Menurut (Priyatno, 2016), autokorelasi adalah keadaan dimana terjadinya korelasi dari residual untuk pengamatan satu dengan pengamatan yang lain yang disusun menurut runtun waktu. Model regresi yang baik mensyaratkan tidak adanya masalah autokorelasi. Uji Autokorelasi bertujuan untuk menguji apakah dalam suatu model suatu regresi linier ada korelasi antara pengganggu pada periode $t$ dengan kesalahan pada periode $\mathrm{t}-1$, jika ada korelasi maka dinamakan ada masalah autokolerasi.

Uji autokorelasi dapat dilakukan dengan menggunakan metode Uji Run Test. Dasar pengambilan keputusannya adalah jika nilai sig. lebih besar dari 0,05, maka model regresi bebas dari gejala autokorelasi.

○ Uji Heteroskedastisitas

Menurut (Priyatno, 2016), heteroskedastisitas adalah keadaan dimana terjadinya ketidaksamaan varian dari residual pada model regresi. Jika varians dari residual dari satu pengamatan ke pengamatan lain tetap, maka disebut homoskesdastisitas. Jika varians berbeda, maka disebut heteroskedastisitas. Model regresi yang baik adalah model yang tidak terjadi masalah heteroskedastisitas.

Untuk mendeteksi gejala heteroskedastisitas dalam persamaan regresi digunakan metode Uji Spearman. Dasar pengambilan keputusan dalam Uji Heteroskedastisitas mengunakan metode Uji Spearman, yaitu:

a) Jika nilai sig. lebih kecil dari 0,05, maka terdapat gejala heteroskedastisitas.

b) Sebaliknya, jika nilai sig. lebih besar dari 0,05, maka tidak terdapat gejala heteroskedastisitas.

\section{- Analisis Regresi Linier Berganda}

Menurut (Sujarweni, 2017), regresi linier berganda adalah regresi yang memiliki satu variabel dependen dan dua atau lebih variabel independen. Regresi linier berganda adalah hubungan linier antara dua atau lebih variabel independen $(X)$ dengan variabel dependen (Y). Analisis regresi linier berganda digunakan untuk mengetahui besarnya pengaruh antara dua atau lebih variabel independen dengan satu variabel dependen. Untuk menjelaskan permasalahan dalam penelitian ini, maka digunakan analisis regresi linier berganda untuk mengetahui besarnya pengaruh corporate governance (CG) dan corporate reputation (CR) dimana diwakili oleh financial (FIN), image (IMG), dan corporate social responsibility (CSR) terhadap employee engangement (EE).

Bentuk persamaan regresi linier berganda adalah sebagai berikut: 


$$
\mathrm{Y}=\alpha+\beta_{1} \mathrm{X}_{1}+\beta_{2} \mathrm{X}_{2}+\beta_{3} \mathrm{X}_{3}+\beta_{4} \mathrm{X}_{4}
$$

Keterangan :

$$
\begin{array}{ll}
\mathrm{Y} & =\text { Employee Engangement }(\mathrm{EE}) \\
\alpha & =\text { Konstanta } \\
\beta_{1}-\beta_{4} & =\text { Koefisien Regresi } \\
\mathrm{X}_{1} & =\text { Corporate Governance (CG) } \\
\mathrm{X}_{2} & =\text { Financial (FIN) } \\
\mathrm{X}_{3} & =\text { Image (IMG) } \\
\mathrm{X}_{4} & =\text { Corporate Social Responsibility (CSR) }
\end{array}
$$

\section{○ Uji Hipotesis}

Menurut (Quadratullah, 2014), Uji Hipotesis adalah prosedur yang digunakan untuk menguji validasi hipotesis statistik suatu populasi dengan menggunakan data dari sampel populasi. Penulis menggunakan bantuan SPSS versi 25 dalam melakukan pengujian hipotesis. Tingkat signifikan $(\alpha)$ yang ditetapkan adalah sebesar 5 persen.

$\circ \quad$ Uji Parsial (Uji T)

Menurut (Ghozali, 2011), Uji T digunakan untuk menguji seberapa jauh pengaruh variabel independen yang digunakan dalam penelitian ini secara individual dalam menerangkan variabel dependen secara parsial. Uji parsial dilakukan dengan membandingkan antara nilai t hitung dengan nilai $\mathrm{t}$ tabel dengan menggunakan tingkat signifikan $(\alpha)$, yaitu 0,05 . Jika signifikansi kurang dari 0,05 , maka hipotesis alternatif yang menyatakan bahwa secara parsial variabel independen berpengaruh signifikan terhadap variabel dependen diterima.

○ Uji Simultan (Uji F)

Menurut (Priyatno, 2012), Uji F digunakan untuk menguji apakah variabel independen secara simultan berpengaruh terhadap variabel dependen. Uji simultan dilakukan dengan membandingkan antara nilai $\mathrm{F}$ hitung dengan nilai $\mathrm{F}$ tabel dengan menggunakan tingkat signifikan $(\alpha)$, yaitu 0,05. Jika signifikansi kurang dari 0,05, maka hipotesis alternatif yang menyatakan bahwa secara simultan variabel independen berpengaruh signifikan terhadap variabel dependen diterima.

○ Koefisien Determinasi $\left(\mathbf{R}^{2}\right)$

Menurut (Priyatno, 2016), analisis $\mathrm{R}^{2}$ (R Square) atau koefisien determinasi digunakan untuk mengetahui persentase sumbangan pengaruh variabel independen secara bersama-sama terhadap variabel dependen. Nilai koefisien determinasi adalah antara nol dan satu. Jika nilai $\mathrm{R}^{2}$ semakin mendekati 1, maka variabel independen mampu memberikan hampir semua informasi yang dibutuhkan untuk memprediksi variasi variabel dependen. Sebaliknya, jika nilai $\mathrm{R}^{2}$ kecil, maka kemampuan variabel independen dalam memberikan informasi pada variasi variabel dependen sangat terbatas. 


\section{Operasional Variabel}

Tabel 1. Operasionalisasi Variabel

\begin{tabular}{|l|l|c|}
\hline \multicolumn{1}{|c|}{ Variabel } & \multicolumn{1}{|c|}{ Domain } & Skala \\
\hline $\begin{array}{l}\text { Corporate Governance } \\
\text { (Sarfraz et al., 2018) }\end{array}$ & & Likert 1-5 \\
\hline \multirow{2}{*}{$\begin{array}{l}\text { Corporate Reputation } \\
\text { (Sarfraz et al., 2018) }\end{array}$} & Kinerja Keuangan Perusahaan & Likert 1-5 \\
\cline { 2 - 3 } & Corporate Image & Likert 1-5 \\
\cline { 2 - 3 } & Aktifitas CSR Perusahaan & Likert 1-5 \\
\hline $\begin{array}{l}\text { Employee Engagement } \\
\text { (Carrillo et al., 2017) }\end{array}$ & & Likert 1-5 \\
\hline
\end{tabular}

Sumber: Olahan Peneliti

\section{HASIL DAN PEMBAHASAN HASIL}

\section{Profil Responden}

Berdasarkan hasil survey yang dilakukan, maka profil dari responden adalah sebagai berikut.

Tabel 2. Profil Responden

\begin{tabular}{|c|c|c|c|c|c|c|c|}
\hline \multicolumn{2}{|c|}{ Keterangan } & \multicolumn{4}{|c|}{ Jenis Kelamin } & \multirow{2}{*}{\multicolumn{2}{|c|}{ Total }} \\
\hline \multirow{2}{*}{\begin{tabular}{l}
\multicolumn{1}{c}{ Usia } \\
Dibawah 25 \\
tahun
\end{tabular}} & \multirow{2}{*}{$\begin{array}{c}\text { Lama Bekerja } \\
\text { kurang dari } 2 \text { tahun }\end{array}$} & \multicolumn{2}{|c|}{ Perempuan } & \multicolumn{2}{|c|}{ Laki-Laki } & & \\
\hline & & 2 & $1.75 \%$ & 3 & $2.63 \%$ & 5 & $4.39 \%$ \\
\hline & $2-5$ tahun & 1 & $0.88 \%$ & 0 & $0.00 \%$ & 1 & $0.88 \%$ \\
\hline & lebih dari 5 tahun & 1 & $0.88 \%$ & 1 & $0.88 \%$ & 2 & $1.75 \%$ \\
\hline \multicolumn{2}{|r|}{ Jumlah } & 4 & $3.51 \%$ & 4 & $3.51 \%$ & 8 & $7.02 \%$ \\
\hline \multirow[t]{3}{*}{$26-35$ tahun } & kurang dari 2 tahun & 4 & $3.51 \%$ & 2 & $1.75 \%$ & 6 & $5.26 \%$ \\
\hline & $2-5$ tahun & 12 & $10.53 \%$ & 14 & $12.28 \%$ & 26 & $22.81 \%$ \\
\hline & lebih dari 5 tahun & 11 & $9.65 \%$ & 14 & $12.28 \%$ & 25 & $21.93 \%$ \\
\hline \multicolumn{2}{|r|}{ Jumlah } & 27 & $23.68 \%$ & 30 & $26.32 \%$ & 57 & $50.00 \%$ \\
\hline \multirow[t]{3}{*}{$36-45$ tahun } & kurang dari 2 tahun & 1 & $0.88 \%$ & 1 & $0.88 \%$ & 2 & $1.75 \%$ \\
\hline & $2-5$ tahun & 3 & $2.63 \%$ & 3 & $2.63 \%$ & 6 & $5.26 \%$ \\
\hline & lebih dari 5 tahun & 8 & $7.02 \%$ & 25 & $21.93 \%$ & 33 & $28.95 \%$ \\
\hline \multicolumn{2}{|r|}{ Jumlah } & 12 & $10.53 \%$ & 29 & $25.44 \%$ & 41 & $35.96 \%$ \\
\hline \multirow[t]{3}{*}{ Diatas 45 tahun } & kurang dari 2 tahun & 1 & $0.88 \%$ & 0 & $0.00 \%$ & 1 & $0.88 \%$ \\
\hline & $2-5$ tahun & 0 & $0.00 \%$ & 1 & $0.88 \%$ & 1 & $0.88 \%$ \\
\hline & lebih dari 5 tahun & 1 & $0.88 \%$ & 5 & $4.39 \%$ & 6 & $5.26 \%$ \\
\hline \multicolumn{2}{|r|}{ Jumlah } & 2 & $1.75 \%$ & 6 & $5.26 \%$ & 8 & $7.02 \%$ \\
\hline \multicolumn{2}{|c|}{ Total } & 45 & $39.47 \%$ & 69 & $60.53 \%$ & 114 & $100.00 \%$ \\
\hline
\end{tabular}

Sumber: Olahan Peneliti

Berdasarkan Tabel 2, dapat dilihat bahwa total responden adalah sebanyak 114 orang dimana mayoritas berjenis kelamin laki-laki $(60,53 \%)$ sedangkan perempuan hanya sebesar 39,47\%. Responden sebagian besar berusia 26-35 tahun (50\%), diikuti oleh usia 36-45 tahun $(35,98 \%)$, sedangkan untuk usia dibawah 25 tahun dan diatas 45 tahun sama-sama sebesar $7,02 \%$. 


\section{Statistik Deskriptif}

Tabel 3. Hasil Analisis Deskriptif

\begin{tabular}{|l|c|r|r|r|r|}
\hline & $\boldsymbol{N}$ & \multicolumn{1}{|c|}{ Minimum } & Maximum & \multicolumn{1}{c|}{ Mean } & Std. Deviation \\
\hline CG & 114 & 1.0769 & 5.0000 & 3.615385 & 0.6716142 \\
\hline FIN & 114 & 1.4000 & 5.0000 & 3.859649 & 0.6357658 \\
\hline IMG & 114 & 1.1667 & 5.0000 & 3.881579 & 0.7024762 \\
\hline CSR & 114 & 1.0000 & 5.0000 & 3.573684 & 0.7176723 \\
\hline EE & 114 & 1.2727 & 5.0000 & 3.919458 & 0.5710998 \\
\hline Valid N (listwise) & 114 & & & & \\
\hline
\end{tabular}

Sumber: Hasil Olah Data SPSS 25

Berdasarkan data Tabel 3, maka hasil analisis deskriptif dapat dijelaskan sebagai berikut:

1. Corporate Governance (CG) memiliki nilai minimum sebesar 1,0769, nilai maksimum sebesar 5, nilai rata-rata sebesar 3,615385, dan standar deviasi sebesar 0,6716142.

2. Financial (FIN) memiliki nilai minimum sebesar 1.4000 , nilai maksimum sebesar 5, nilai rata-rata sebesar 3.859649, dan standar deviasi sebesar 0,6357658.

3. Image (IMG) memiliki nilai minimum sebesar 1.1667, nilai maksimum sebesar 5, nilai ratarata sebesar 3.881579, dan standar deviasi sebesar 0,7024762.

4. Corporate Social Responsibility (CSR) memiliki nilai minimum sebesar 1, nilai maksimum sebesar 5, nilai rata-rata sebesar 3,573684, dan standar deviasi sebesar 0,7176723.

5. Employee Engangement (CSR) memiliki nilai minimum sebesar 1,2727, nilai maksimum sebesar 5, nilai rata-rata sebesar 3,919458, dan standar deviasi sebesar 0,5710998.

\section{Pembahasan}

\section{Uji Asumsi Klasik}

○ Uji Normalitas

Pada penelitian ini uji normalitas menggunakan uji one sample kolmogorov-smirnov. Model regresi dapat dikatakan berdistribusi normal jika signifikan lebih besar dari 0.05 dan tidak berdistribusi normal jika signifikan lebih kecil dari 0.05 .

Tabel 4. Hasil Uji Normalitas

\begin{tabular}{|ll|r|}
\hline & & Unstandardized Residual \\
\hline$N$ & & 114 \\
\hline Normal Parameters ${ }^{a, b}$ & Mean & .0000000 \\
\cline { 2 - 3 } & Std. Deviation & .33065398 \\
\hline Most Extreme Differences & Absolute & .067 \\
\cline { 2 - 3 } & Positive & .048 \\
\cline { 2 - 3 } & Negative & -.067 \\
\hline Test Statistic & & .067 \\
\hline Asymp. Sig. (2-tailed) & & $.200 \mathrm{c}, \mathrm{d}$ \\
\hline
\end{tabular}

a. Test distribution is Normal.

b. Calculated from data.

c. Lilliefors Significance Correction.

d. This is a lower bound of the true significance. Sumber: Hasil Olah Data SPSS 25 
Berdasarkan hasil Tabel 4, dapat diketahui bahwa nilai Kolmogorov-Smirnov dan nilai signifikan (Asymp. Sig. 2-tailed) lebih besar dari 0,05, yaitu sebesar 0,200. Kondisi ini menunjukkan bahwa data pada variabel penelitian ini terdistribusi normal.

\section{○ Uji Multikolinearitas}

Model regresi yang baik mensyaratkan tidak terjadi masalah multikolinearitas. Metode yang digunakan untuk mendeteksi ada tidaknya multikolinearitas adalah dengan melihat nilai tolerance dan variance inflation factor (VIF) pada hasil regresi linier. Jika nilai tolerance lebih dari 0,1 dan nilai VIF kurang dari 10, maka tidak terjadi multikolinearitas.

Tabel 5. Hasil Uji Multikolinearitas

\begin{tabular}{|c|c|c|c|c|c|c|c|c|}
\hline & \multirow{2}{*}{ Model } & \multicolumn{2}{|c|}{$\begin{array}{l}\text { Unstandardized } \\
\text { Coefficients }\end{array}$} & \multirow{2}{*}{$\begin{array}{c}\begin{array}{c}\text { Standardized } \\
\text { Coefficients }\end{array} \\
\text { Beta }\end{array}$} & \multirow{2}{*}{$t$} & \multirow{2}{*}{ Sig. } & \multicolumn{2}{|c|}{$\begin{array}{l}\text { Collinearity } \\
\text { Statistics }\end{array}$} \\
\hline & & B & $\begin{array}{l}\text { Std. } \\
\text { Error }\end{array}$ & & & & Tolerance & VIF \\
\hline \multirow[t]{5}{*}{1} & (Constant) & 1.109 & .202 & & 5.479 & .000 & & \\
\hline & $C G$ & .471 & .086 & .554 & 5.507 & .000 & .304 & 3.291 \\
\hline & $\overline{F I N}$ & .226 & .084 & 251 & 2.688 & .008 & .352 & 2.845 \\
\hline & $I M G$ & .087 & .082 & .107 & 1.067 & .288 & .303 & 3.301 \\
\hline & CSR & -.029 & .083 & -.036 & -.347 & .730 & .280 & 3.565 \\
\hline
\end{tabular}

a. Dependent Variable: EE

Sumber: Hasil Olah Data SPSS 25

Berdasarkan hasil Tabel 5, dapat diketahui bahwa semua variabel memiliki nilai Tolerance yang lebih besar dari 0,1 dan nilai VIF yang kurang dari 10. Kondisi ini menunjukkan bahwa model regresi terbebas dari masalah multikolinearitas.

\section{○ Uji Autokorelasi}

Uji autokorelasi dapat dilakukan dengan menggunakan metode run test. Dasar pengambilan keputusannya adalah jika signifikan (Asymp. Sig. 2-tailed) lebih besar dari 0,05 , maka model regresi bebas dari gejala autokorelasi.

Tabel 6. Hasil Uji Autokorelasi

\begin{tabular}{|l|r|}
\hline & Unstandardized Residual \\
\hline Test Value $^{a}$ & -.01003 \\
\hline Cases $<$ Test Value & 57 \\
\hline Cases $>=$ Test Value & 57 \\
\hline Total Cases & 114 \\
\hline Number of Runs & 57 \\
\hline Z & -.188 \\
\hline Asymp. Sig. (2-tailed) & .851 \\
\hline
\end{tabular}

\section{a. Median}

Sumber: Hasil Olah Data SPSS 25

Berdasarkan hasil Tabel 6, dapat diketahui bahwa nilai signifikan (Asymp. Sig. 2tailed) lebih besar dari 0,05, yaitu sebesar 0,851. Kondisi ini menunjukkan bahwa data pada variabel penelitian ini tidak memiliki gejala autokorelasi. 
○ Uji Heteroskedastisitas

Untuk mendeteksi gejala heteroskedastisitas dalam persamaan regresi digunakan metode uji Spearman. Dasar pengambilan keputusan dalam uji heteroskedastisitas mengunakan metode uji Spearman adalah jika nilai Sig. lebih kecil dari 0,05 maka terdapat gejala heteroskedastisitas, sebaliknya jika nilai Sig. lebih besar dari 0,05 maka tidak terdapat gejala heteroskedastisitas.

Tabel 7. Hasil Uji Heterokedastisitas

\begin{tabular}{|c|c|c|c|c|c|c|c|}
\hline & & & $C G$ & FIN & IMG & CSR & $\begin{array}{c}\text { Unstandardized } \\
\text { Residual }\end{array}$ \\
\hline \multirow[t]{23}{*}{ Spearman's rho } & \multirow[t]{4}{*}{$C G$} & Correlation & 1.0 & .68 & $.689^{*}$ & $.757^{*}$ & -.021 \\
\hline & & Coefficient & 00 & $5^{* *}$ & & & \\
\hline & & Sig. (2-tailed) & & $\begin{array}{r}.00 \\
0\end{array}$ & .000 & .000 & .821 \\
\hline & & $N$ & 114 & 114 & 114 & 114 & 114 \\
\hline & \multirow[t]{4}{*}{ FIN } & Correlation & .68 & 1.0 & $.736^{*}$ & $.702^{*}$ & -.006 \\
\hline & & Coefficient & $5^{* *}$ & 00 & & & \\
\hline & & Sig. (2-tailed) & $\begin{array}{r}.00 \\
0\end{array}$ & & .000 & .000 & .946 \\
\hline & & $N$ & 114 & 114 & 114 & 114 & 114 \\
\hline & \multirow[t]{4}{*}{$I M G$} & Correlation & .68 & .73 & 1.00 & $.702^{*}$ & .028 \\
\hline & & Coefficient & $9^{* *}$ & $6^{* *}$ & 0 & & \\
\hline & & Sig. (2-tailed) & $\begin{array}{r}.00 \\
0\end{array}$ & $\begin{array}{r}.00 \\
0\end{array}$ & & .000 & .766 \\
\hline & & $N$ & 114 & 114 & 114 & 114 & 114 \\
\hline & \multirow[t]{5}{*}{$C S R$} & Correlation & .75 & .70 & $.702^{*}$ & 1.00 & -.030 \\
\hline & & Coefficient & $7^{* *}$ & $2^{* *}$ & & 0 & \\
\hline & & Sig. (2-tailed) & .00 & .00 & .000 & & .755 \\
\hline & & & 0 & 111 & 111 & & 111 \\
\hline & & $N$ & 114 & 114 & 114 & 114 & 114 \\
\hline & \multirow{6}{*}{$\begin{array}{l}\text { Unstandardized } \\
\text { Residual }\end{array}$} & Correlation & - & - & .028 & & 1.000 \\
\hline & & Coefficient & .02 & .00 & & .030 & \\
\hline & & & 1 & 6 & & & \\
\hline & & Sig. (2-tailed) & .82 & .94 & .766 & .755 & \\
\hline & & & 1 & 6 & & & \\
\hline & & $N$ & 114 & 114 & 114 & 114 & 114 \\
\hline
\end{tabular}

**. Correlation is significant at the 0.01 level (2-tailed).

Sumber: Hasil Olah Data SPSS 25

Berdasarkan hasil Tabel 7, bahwa nilai signifikan pada variabel CG, FIN, IMG, dan CSR masing-masing sebesar 0,821, 0,946, 0,766 dan 0,755. Karena signifikan lebih besar dari 0,05, maka dapat disimpulkan bahwa penelitian ini terbebas dari gejala heteroskedastisitas.

\section{○ Regresi Linier Berganda}

Regresi linier berganda merupakan suatu persamaan yang menggambarkan hubungan antara dua atau lebih variabel bebas dengan satu variabel terikat. Regresi linier berganda diterapkan pada penelitian ini untuk mengetahui apakah terdapat hubungan antara corporate governance (CG) dan corporate reputation (CR) yang diwakili oleh 
financial (FIN), image (IMG), dan corporate social responsibility (CSR) dengan employee engangement (EE) serta mengetahui seberapa besar pengaruhnya.

Tabel 8. Hasil Analisis Regresi Linear Berganda

\begin{tabular}{|c|c|c|c|c|c|c|}
\hline & \multirow[t]{2}{*}{ Model } & \multicolumn{2}{|c|}{$\begin{array}{c}\text { Unstandardized } \\
\text { Coefficients }\end{array}$} & \multirow{2}{*}{$\begin{array}{c}\begin{array}{c}\text { Standardized } \\
\text { Coefficients }\end{array} \\
\text { Beta }\end{array}$} & \multirow[t]{2}{*}{$t$} & \multirow[t]{2}{*}{ Sig. } \\
\hline & & $\boldsymbol{B}$ & Std. Error & & & \\
\hline \multirow[t]{5}{*}{1} & (Constant) & 1.109 & .202 & & 5.479 & .000 \\
\hline & $C G$ & .471 & .086 & .554 & 5.507 & .000 \\
\hline & FIN & .226 & .084 & .251 & 2.688 & .008 \\
\hline & $I M G$ & .087 & .082 & .107 & 1.067 & .288 \\
\hline & $C S R$ & -.029 & .083 & -.036 & -.347 & .730 \\
\hline
\end{tabular}

a. Dependent Variable: EE

Sumber: Hasil Olah Data SPSS 25

Dari hasil pengujian pada Tabel 8, maka terbentuk persamaan regresi sebagai berikut:

$$
\mathrm{EE}=1,109+0,471 \mathrm{CG}+0,226 \mathrm{FIN}+0,087 \mathrm{IMG}-0,029 \mathrm{CSR}
$$

Berdasarkan model regresi linier berganda diatas, maka dapat dijelaskan bahwa:

1. Nilai konstanta sebesar 0,120 menyatakan nilai EE jika variabel CG, FIN, IMG, dan CSR bernilai nol.

2. Nilai Koefisien CG sebesar 0,471. Tanda positif menunjukkan bahwa CG mempunyai hubungan yang searah dengan EE. Hal ini berarti bahwa jika variabel independen lainnya tetap dan CG mengalami peningkatan sebesar satu, maka EE akan mengalami peningkatan sebesar 0,471 .

3. Nilai Koefisien FIN sebesar 0,226. Tanda positif menunjukkan bahwa FIN mempunyai hubungan yang searah dengan EE. Hal ini berarti bahwa jika variabel independen lainnya tetap dan FIN mengalami peningkatan sebesar satu, maka EE akan mengalami peningkatan sebesar 0,226.

4. Nilai Koefisien IMG sebesar 0,087. Tanda positif menunjukkan bahwa IMG mempunyai hubungan yang searah dengan EE. Hal ini berarti bahwa jika variabel independen lainnya tetap dan IMG mengalami peningkatan sebesar satu, maka EE akan mengalami peningkatan sebesar 0,087.

5. Nilai Koefisien CSR sebesar -0,029. Tanda positif menunjukkan bahwa CSR mempunyai hubungan yang berlawanan dengan EE. Hal ini berarti bahwa jika variabel independen lainnya tetap dan CSR mengalami peningkatan sebesar satu, maka EE akan mengalami penurunan sebesar 0,029.

\section{Uji Hipotesis}

\section{○ Uji Parsial (Uji t)}

Uji parsial atau uji t dilakukan untuk mengetahui apakah variabel bebas (independent variable) berpengaruh secara parsial atau individual terhadap variabel terikat (dependent variable).

Kriteria pengujian untuk uji t dengan tingkat signifikan $\alpha=0,05$ adalah jika probabilitas $<0,05$ maka hipotesis diterima, sedangkan jika probabilitas $>0,05$ maka hipotesis ditolak. 


\begin{tabular}{|c|c|c|c|c|c|c|}
\hline & \multirow[t]{2}{*}{ Model } & \multicolumn{2}{|c|}{$\begin{array}{c}\text { Unstandardized } \\
\text { Coefficients }\end{array}$} & \multirow{2}{*}{$\begin{array}{c}\begin{array}{c}\text { Standardized } \\
\text { Coefficients }\end{array} \\
\text { Beta }\end{array}$} & \multirow[t]{2}{*}{$t$} & \multirow[t]{2}{*}{ Sig. } \\
\hline & & $\boldsymbol{B}$ & Std. Error & & & \\
\hline \multirow[t]{5}{*}{1} & (Constant) & 1.109 & .202 & & 5.479 & .000 \\
\hline & $C G$ & .471 & .086 & .554 & 5.507 & .000 \\
\hline & FIN & .226 & .084 & .251 & 2.688 & .008 \\
\hline & $I M G$ & .087 & .082 & .107 & 1.067 & .288 \\
\hline & CSR & -.029 & .083 & -.036 & -.347 & .730 \\
\hline
\end{tabular}

a. Dependent Variable: EE

Sumber: Hasil Olah Data SPSS 25

Berdasarkan Tabel 9, dapat dijelaskan pengaruh variabel bebas secara parsial terhadap variabel terikat adalah sebagai berikut:

- Pengaruh corporate governance dengan employee engangement

Rumusan hipotesis adalah sebagai berikut:

H1: Corporate Governance bepengaruh positif terhadap Employee Engangement.

Berdasarkan pada Tabel 9, dapat dilihat bahwa hasil pengujian menunjukkan nilai signifikan CG sebesar 0,000 lebih kecil dari 0,05 sehingga hipotesis diterima. Hal tersebut memiliki arti bahwa corporate governance (CG) secara parsial berpengaruh signifikan terhadap employee engangement (EE). Penelitian juga menunjukkan koefisien regresi sebesar 0,471 yang berarti CG berpengaruh positif terhadap EE.

- Pengaruh corporate reputation dengan employee engangement

Rumusan hipotesis adalah sebagai berikut:

H2: Corporate Reputation bepengaruh positif terhadap Employee Engangement

Pada penelitian ini, corporate reputation (CR) diwakili oleh financial (FIN), image (IMG), dan corporate social responsibility (CSR). Berdasarkan pada Tabel 9, dapat dilihat bahwa hasil pengujian menunjukkan nilai signifikan FIN sebesar 0,008 lebih kecil dari 0,05 sehingga hipotesis diterima. Hal tersebut memiliki arti bahwa FIN secara parsial berpengaruh signifikan terhadap EE. Penelitian juga menunjukkan koefisien regresi sebesar 0,226 yang berarti FIN berpengaruh positif terhadap EE.

Hasil pengujian menunjukkan nilai signifikan IMG sebesar 0,288 lebih besar dari 0,05 sehingga hipotesis ditolak, memiliki arti bahwa IMG secara parsial tidak berpengaruh signifikan terhadap EE. Penelitian juga menunjukkan koefisien regresi sebesar 0,087 yang berarti IMG berpengaruh positif terhadap EE.

Hasil pengujian menunjukkan nilai signifikan CSR sebesar 0,730 lebih besar dari 0,05 sehingga hipotesis ditolak, yang berarti bahwa CSR secara parsial tidak berpengaruh signifikan terhadap EE. Penelitian juga menunjukkan koefisien regresi sebesar -0,029 yang berarti CSR berpengaruh negatif terhadap EE.

\section{○ Uji Simultan (Uji F)}

Uji simultan atau uji $\mathrm{F}$ dilakukan untuk mengetahui apakah variabel bebas (independent variable) berpengaruh secara simultan atau bersama-sama terhadap variabel terikat (dependent variable). Hipotesis yang akan diuji adalah: 
H3: Corporate Governance dan Corporate Reputation secara simultan bepengaruh positif terhadap Employee Engangement.

Kriteria pengujian untuk uji $\mathrm{F}$ dengan tingkat signifikan $\alpha=0,05$ adalah jika probabilitas $<$ 0,05 maka hipotesis diterima, sedangkan jika probabilitas $>$ 0,05 maka hipotesis ditolak.

Tabel 10. Hasil Uji F (Simultan)

\begin{tabular}{|c|c|c|c|c|c|c|}
\hline & Model & Sum of Squares & $d f$ & Mean Square & $\boldsymbol{F}$ & Sig. \\
\hline \multirow[t]{3}{*}{1} & Regression & 24.501 & 4 & 6.125 & 54.041 & $.000^{\mathrm{b}}$ \\
\hline & Residual & 12.355 & 109 & .113 & & \\
\hline & Total & 36.856 & 113 & & & \\
\hline
\end{tabular}

a. Dependent Variable: EE

b. Predictors: (Constant), CG, FIN, IMG, CSR

Sumber: Hasil Olah Data SPSS 25

Berdasarkan pada Tabel 10, dapat dilihat bahwa hasil pengujian menunjukkan nilai signifikan sebesar 0,000 lebih kecil dari 0,05 sehingga hipotesis diterima. Hal tersebut memiliki arti bahwa variabel bebas yang terdiri dari corporate governance (CG) dan corporate reputation (CR) dimana diwakili oleh financial (FIN), image (IMG), dan corporate social responsibility (CSR) secara simultan berpengaruh terhadap employee engangement (EE).

\section{Koefisien determinasi}

Nilai koefisien determinasi adalah antara nol dan satu. Nilai $\mathrm{R}^{2}$ yang semakin mendekati 1, maka variabel independen mampu memberikan hampir semua informasi yang dibutuhkan untuk memprediksi variasi variabel dependen. Sebaliknya jika nilai $\mathrm{R}^{2}$ yang kecil, maka kemampuan variabel independen dalam memberikan informasi pada variasi variabel dependen sangat terbatas.

Tabel 11. Hasil Analisis Koefisien Determinasi

\begin{tabular}{|l|r|r|r|r|}
\hline Model & $\boldsymbol{R}$ & $\boldsymbol{R}$ Square & Adjusted $\boldsymbol{R}$ Square & Std. Error of the Estimate \\
\hline 1 & $.815^{\mathrm{a}}$ & .665 & .652 & .3366664 \\
\hline
\end{tabular}

a. Predictors: (Constant), CG, FIN, IMG, CSR

b. Dependent Variable: EE

Sumber: Hasil Olah Data SPSS 25

Berdasarkan data pada Tabel 11, diperoleh angka $\mathrm{R}^{2}$ sebesar 0,652 atau 65,2 persen $(0,652 \times 100$ persen). Hal ini menunjukkan bahwa CG, FIN, IMG, dan CSR secara simultan mempengaruhi EE sebesar 65,2 persen. Sedangkan sisanya 34,8 persen (100 persen - 65,2 persen) dipengaruhi oleh faktor-faktor lain yang tidak dianalisis dalam penelitian ini.

\section{Interpretasi Hasil Penelitian}

- Pengaruh corporate governance dengan employee engangement

Dengan total responden adalah sebanyak 114 orang dimana berjenis kelamin lakilaki sebanyak 69 orang $(60,53 \%)$ sedangkan perempuan sebanyak 45 orang $(39,47 \%)$, penelitian menunjukkan bahwa corporate governance (CG) secara parsial berpengaruh signifikan dan positif terhadap employee engangement (EE). 
Hasil penelitian ini dapat dijelaskan karena tata kelola perusahaan (CG) yang baik merupakan hasil dari pihak manajemen dalam mengelola perusahaan dengan baik. Pengelolaan yang baik tersebut akan membentuk suasana dan pengendalian yang memberikan tatanan kerja yang baik. Tatanan kerja yang baik ini akan membuat karyawan dalam perusahaan mampu bekerja secara efektif dan efisien sehingga keterikatan karyawan (EE) dalam perusahaan semakin meningkat.

\section{- Pengaruh corporate reputation dengan employee engangement}

Dengan total responden adalah sebanyak 114 orang dimana berjenis kelamin lakilaki sebanyak 69 orang $(60,53 \%)$ sedangkan perempuan sebanyak 45 orang $(39,47 \%)$, penelitian menunjukkan bahwa corporate reputation (CR) yang diwakili oleh financial (FIN) berpengaruh signifikan dan positif terhadap employee engangement (EE). Corporate reputation (CR) yang diwakili oleh image (IMG) secara parsial tidak berpengaruh signifikan dan positif terhadap EE. Corporate reputation (CR) yang diwakili oleh corporate social responsibility (CSR) secara parsial tidak berpengaruh signifikan, dan negatif terhadap EE.

Hasil penelitian ini dapat dijelaskan karena reputasi perusahaan (CR) yang baik merupakan hasil dari kinerja perusahaan. Reputasi perusahaan ini dipengaruhi oleh beberapa hal, beberapa diantaranya adalah kekuatan finansial perusahaan, image perusahaan, dan responsibilitas sosial perusahaan. Finansial serta image perusahaan yang baik akan membuat reputasi di mata pihak yang berkepentingan seperti kreditor maupun pemegang saham menjadi baik. Semakin tinggi reputasi perusahaan, karyawan yang berkerja dalam perusahaan juga dipandang lebih tinggi oleh masyarakat luas sehingga karyawan tersebut akan lebih termotivasi untuk bekerja di dalam perusahaan. Hal ini akan membuat keterlibatan karyawan (EE) di dalam perusahaan semakin meningkat.

- Pengaruh corporate governance dan corporate reputation dengan employee engangement

Dengan total responden adalah sebanyak 114 orang dimana berjenis kelamin lakilaki sebanyak 69 orang $(60,53 \%)$ sedangkan perempuan sebanyak 45 orang $(39,47 \%)$, penelitian menunjukkan bahwa corporate governance (CG) dan corporate reputation (CR) dimana diwakili oleh financial (FIN), image (IMG), dan corporate social responsibility (CSR) secara simultan berpengaruh sebesar 65,2 persen terhadap employee engangement (EE).

Hasil penelitian ini dapat dijelaskan karena tata kelola (CG) dan reputasi perusahaan (CR) yang baik membuat suasana kerja di perusahaan menjadi kondusif, sehingga karyawan lebih termotivasi untuk bekerja yang pada akhirnya membuat keterlibatan karyawan dalam perusahaan meningkat.

\section{KESIMPULAN}

Berdasarkan hasil analisis regresi linier berganda, dapat disimpulkan pengaruh antara corporate governance (CG) dan corporate reputation (CR) dimana diwakili oleh financial (FIN), image (IMG), dan corporate social responsibility (CSR) dengan employee engangement (EE) adalah sebagai berikut:

1. Hasil pengujian menunjukkan corporate governance (CG) secara parsial berpengaruh signifikan dan positif terhadap employee engangement (EE). 
2. Hasil pengujian menunjukkan corporate reputation (CR) secara parsial berpengaruh signifikan dan positif terhadap employee engangement (EE).

3. Hasil pengujian menunjukkan corporate governance (CG) dan corporate reputation (CR) secara simultan berpengaruh signifikan dan positif terhadap employee engangement (EE).

\section{SARAN}

Berdasarkan hasil penelitian ini maka peneliti menyarankan sebagai berikut:

- Perlu dilakukan penelitian lebih lanjut dengan menggunakan variabel penelitian, periode waktu penelitian, dan sampel penelitian yang lebih banyak. Hal ini perlu dilakukan agar dapat diketahui faktor-faktor apa saja yang berpengaruh terhadap EE.

- Perlu dilakukan penelitian EE di industri yang berbeda agar mendapatkan gambaran lebih lengkap tentang peta EE di banyak industri.

- Perlu dilakukan penelitian EE secara berkala dan rutin agar terdapat data pembanding antar waktu yang dapat dipakai pihak manajemen untuk mengevaluasi kebijakankebijakan perusahaan agar tingkat EE terus dapat diperbaiki. 
Volume 24 No 1 Tahun 2020 | 59

\section{DAFTAR PUSTAKA}

Anand, G. (2017). Corporate Excellence through Governance and Employee Engagement: a Brief Analysis. 8, 554-562.

Arayssi, M., \& Jizi, M. I. (2019). Does corporate governance spillover fi rm performance ? A study of valuation of MENA companies. Social Responsibility Journal, 15(5), 597-620. doi: https://doi.org/10.1108/SRJ-06-2018-0157

Bae, S. M., Masud, M. A. K., \& Kim, J. D. (2018). A cross-country investigation of corporate governance and corporate sustainability disclosure: A signaling theory perspective. Sustainability (Switzerland), 10(8). doi: https://doi.org/10.3390/su10082611

Bawaneh, S. S. (2020). Impact of corporate governance on financial institutions' performance: A board composition case. Asian Economic and Financial Review, 10(1), 54-63. doi: https://doi.org/10.18488/journal.aefr.2020.101.54.63

Bezo, Y., \& Dibra, R. (2020). Corporate governance, analyses and theories: The case of Albania. Academy of Strategic Management Journal, 19(1), 1-15.

Brady, A. K. O., \& Honey, G. (2007). Corporate reputation : perspectives of measuring and managing a principal risk. http://www.cimaglobal.com/Documents/Thought_leadership_docs/Corporate reputation perspectives of measuring and managing a principal risk.pdf

Carrillo, H., Castellano, J. F., \& Keune, T. M. (2017). Employee Engagement in Public Accounting Firms: Getting Millennial Staff Excited about the Work Environment: Certified Public Accountant. The CPA Journal, 87(12), 36-41. https://ssolandingsearch.proquest.com/docview/2186186299?accountid=10297\%0Ahttp://resolver.ebscohost. com/openurl?ctx_ver=Z39.88-2004\&ctx_enc=info:ofi/enc:UTF-

8\&rfr_id=info:sid/ProQ\%3Aabiglobal\&rft_val_fmt=info:ofi/fmt:kev:mtx:journal\&rft.genre=arti cle\&rf

Chaudhary, N., \& Gakhar, K. (2018). Corporate Governance and Financial Performance with a Perspective on Board Size and Frequency of Board Meetings: Empirical Evidence from India. Journal of Applied Management Accounting Research, 8, 21-37. http://search.ebscohost.com/login.aspx?direct=true\&db=bth\&AN=56561324\&site=edslive\&authtype=ip,uid,cookie

Derevianko, O. (2018). Stakeholder engagement to replace traditional activities in reputation management system: Insights from Ukrainian food processing companies. Problems and Perspectives in Management, 16(4), 314-330. doi: https://doi.org/10.21511/ppm.16(4).2018.26

Fauzia, M. (2020, November 5). Indonesia Resmi Resesi, Ekonomi Kuartal III-2020 Minus 3,49 Persen. Diambil kembali dari Kompas.com: https://money.kompas.com/read/2020/11/05/111828826/indonesia-resmi-resesi- 
ekonomi-kuartal-iii-2020-minus-349-persen?page=all

Gatzert, N., \& Schmit, J. (2016). Supporting strategic success through enterprise-wide reputation risk management. doi: https://doi.org/10.1108/JRF-09-2015-0083

Ghozali, Imam. Analisis Multivariate dengan Program IBM SPSS 19, edisi lima Cetakan V. Semarang: Badan Penerbit Universitas Diponegoro, 2011.

Haydon, R. (2020). What Are CEOs Saying About Employee Engagement? Diambil kembali dari decisionwise: https://decision-wise.com/what-are-ceos-saying-about-employee-engagement/

Supply Chain Management, 18(4), 413-429. https://doi.org/10.1108/SCM-06-2012-0222

Lightle, S. S., Castellano, J., Baker, B., \& Sweeney, R. J. (2015). The Role of Corporate Boards in Employee Engagement.

Luis, J., Sánchez, F., Sotorrío, L. L., \& Diez, E. B. (2015). The relationship between corporate social responsibility and corporate reputation in a turbulent environment: Spanish evidence of the Ibex35 firms. 15(4), 563-575. https://doi.org/10.1108/CG-08-2014-0101

Mutnuru, S. (2016). The Role of Internal Controls on Employees 'Engagement in Small Organizations. $7(4)$.

Naseem, M. A., Xiaoming, S., Riaz, S., \& Rehman, R. U. (2017). Board attributes and performance of government-linked companies (GlCs): Evidence from an emerging economy. Corporate Ownership and Control, 14(3), 74-83. https://doi.org/10.22495/cocv14i3art8

Priyatno, Duwi. Belajar Alat Analisis Data dan Cara Pengolahannya Dengan SPSS. Yogyakarta: Gaya Media, 2016.

Priyatno, Duwi. Cara Kilat Belajar Analisis Data dengan SPSS 20. Yogyakarta: Andi, 2012.

Quadratullah, Mohammad Farhan. Statistika Terapan: Teori, Contoh Kasus, dan Aplikasi SPSS. Yogyakarta: Andi Offset, 2014.

Sarfraz, M., Qun, W., Abdullah, M. I., \& Alvi, A. T. (2018). Employees' perception of Corporate Social Responsibility impact on employee outcomes: Mediating role of organizational justice for Small and Medium Enterprises (SMEs). Sustainability (Switzerland), 10(7). https://doi.org/10.3390/su10072429

Sujarweni, V. Wiratna. Analisis Laporan Keuangan. Yogyakarta: Pustaka Baru Press, 2017.

Sugiyono. Metode Penelitian Kuantitatif, Kualitatif, dan R\&D. Bandung: Alfabeta, 2013.

Tong, S. C. (2013). Exploring corporate risk transparency: Corporate risk disclosure and the interplay of corporate reputation, corporate trust and media usage in initial public Offerings. Corporate Reputation Review, 16(2), 131-149. https://doi.org/10.1057/crr.2013.4 